\title{
La influencia de Gregorio Magno en Alberto Magno. Super Dionysii Mysticam Theologiam et Epistulas ${ }^{1}$
}

\author{
Anneliese Meis ssps \\ FACULTAD DE TEOLOGÍA \\ PONTIFICIA UNIVERSIDAD CATÓLICA DE CHILE
}

Si bien la influencia de Gregorio Magno fue decisiva para la historia del pensamiento teológico práctico en la Edad $\mathrm{Media}^{2}$, siendo Gregorio el autor más citado en la STh de Tomás de Aquino después de Agustín ${ }^{3}$, su influencia sobre Alberto Magno no ha sido estudiada recientemente ${ }^{4}$. En efecto, el significado de este gran Padre de la Iglesia del siglo VI-VII (540604) para el Doctor Universalis se delinea en su vasta obra a través de numerosas referencias explícitas, pero emerge con especial nitidez desde las citas que contiene el Super Dionysii Mysticam Theologiam et Epistulas en

1 El presente estudio es parte del Proyecto de Investigación FONDECYT 2010-2011, 1100043.

2 R. WASSELYNCK, «Les "Moralia in Job" dans les ouvrages de morale du haut moyen âge latin», RThAM 31 (1964) 5-31; IDEM, «La présence des Moralia de S. Grégoire le Grand dans les ouvrages de morale du XII siécle», RThAM 32 (1965) 15-204; 35 (1968) 197-240; 36 (1969) 31-45; C. F. GEYER, «Das Hiobbuch im christlichen und nachchristlichen Kontext. Anmerkungen zur Rezeptionsgeschichte», Kairos 28 (1986) 174-193.

3 Cf. M..M. DufeIL, «Ad Mensam Domini: De Sancto Gregorio apud Thomam», en Colloques internationaux du CNRS, Grégoire le Grand (Paris 1986) 607-619.

4 Cf. J. I. M. Vosté, «Sanctus Albertus Magnus in Liberum Job», Divus Thomas 10 (1933) 3-17, especialmente 11-15. El estudio no aporta datos importantes, salvo una caracterización interesante a ambos autores: «Ambo flagrantes zelo pro doctrina, sanctitate et reformatione Ecclesiae. At Albertus vir cathedrae, mens absoluta, Germanus integer austerus; Gregorius vero Romanus, patiens et moderatus, numquam tentans impossibile, et tamen ad intentum finem uniformi constantia perveniens. Hic demum scientia universali et longaeva aetate superatus ab illo» (p. 11). 
cuanto parte del Comentario de Alberto al Corpus Dionisiacum y que también involucran el problema razón y revelación.

No cabe duda de que Gregorio Magno aporta aspectos novedosos a la comprensión de dicho problema, si pensamos en la fórmula Amor ipse notitia est, que encuentra sus célebres reformulaciones en importantes pensadores medievales y actuales ${ }^{5}$. Si, efectivamente, la razón aparece acompañada por el amor hasta tal punto que amor y razón se identifican - amor ipse intellectus est-, la racionalidad propia de esta identificación evoca una singular capacidad para abordar la revelación de Dios, quien se revela en cuanto amor por excelencia, en la medida en que el Padre se comunica a sí mismo en el Hijo por el Espíritu Santo al ser humano en el mundo a través de la historia.

Pese a la relevancia del pensamiento de Gregorio Magno en cuanto aporte a la intelección teológica del problema razón y revelación, cabe admitir que la capacidad especulativa de Gregorio es inferior a la de Agustín ${ }^{6}$. Sin embargo, el autor se orienta de tal forma por el texto bíblico que ante los ojos del lector se plasma un panorama especulativo impresionante que conlleva una singular insistencia práctica ${ }^{7}$ ¿Qué es lo que a Alberto Magno le resulta significativo, cuando cita a Gregorio en su Comentario a la Teología Mística y las once Epistulas de Dionisio Areopagita? ¿Cuál es la influencia del Santo Papa sobre la argumentación albertina? ¿Será

5 Gregorio Magno, Hom in Euang II 7 (27) (CCH SL, 141) 229-238. Se trata de un texto muy importante, tomado de las Homilías a los Evangelios a Jn 15,12. Gregorio mismo informa sobre el origen de aquellas 40 homilías que hizo desde noviembre 590 hasta primavera del 592 en diferentes iglesias romanas. Debido a su débil salud se dejó escribir las primeras 20 homilías y leerlas en su presencia en la iglesia, mientras el segundo libro abarca aquellas homilías hechas por él mismo, cuyo manuscrito el Papa posteriormente revisó igual como lo hizo con las 20 primeras. Se trata por consiguiente de unas homilías de los primeros años y medio de su pontificado. Esta fórmula Amor ipse notitia est ha sido tomado muy en cuenta, no sólo por los pensadores medievales -Sto. Tomás, STh II-II q. 172 la cita dos veces-, sino por otros autores. Cf. A. MeIs, «El significado teológico de la frase "El conocimiento se convierte en amor" (De an et res, PG 46, 96.37) de Gregorio de Nisa y su recepción por Guillermo de Saint Thierry», Teología y Vida, XLIII (2002) 285-302; J. LeCLerCQ, «Actualité de Grégoire le Grand», en Colloques internationaux du CNRS, Grégoire le Grand (Paris 1986) 681-684.

6 J. LAPORTE, «Une théologie systématique chez Grégoire?», en Colloques internationaux du CNRS, Grégoire le Grand (Paris 1986) 235-243.

7 Cf. A. Simon, «El método teológico de Gregorio Magno, el proceso plurisemántico de la analogía metaexegética», Revista Española de Teología, 65 (2005) 5-29. 
aquella insistencia práctica, unida a la contemplación, que no sólo trasunta en la misión ${ }^{8}$, sino que constituye la novedad de la exégesis gregoriana? Dicha novedad, en efecto, «reside en haber mostrado el vínculo estrecho que existe entre el conocimiento de Dios por la Escritura y la práctica de la virtud ${ }^{9}$.

De hecho, Gregorio comenta el texto bíblico ordenadamente ${ }^{10}$ según su sentido histórico literal -quomodo iuxta litteram intelligendus- y alegórico - qualiter ad Christi Ecclesiastique sacramenta referendus-, pero se detiene, con preferencia, en el sentido moral - quo sensu unicuique fidelium sit aptandus ${ }^{11}$-, como lo permiten apreciar, sobre todo, las citas usadas por Alberto Magno en su compleja argumentación en torno a la Mystica Theologia y las Epistulas del Areopagita ${ }^{12}$. En efecto, estas citas son extractos del libro de Job, que Gregorio comenta versículo por versículo, considerándose su primer comentarista ${ }^{13}$. Este libro del A.T. proyecta, de hecho, un especial énfasis en vivir y comprender experiencias existenciales dramáticas, que el personaje veterotestamentario, extraño y fascinante a la vez, articula con un esfuerzo asiduo por lograr una intelección adecuada del misterio de la revelación de Dios en su vida ${ }^{14}$. Gregorio Magno, a su vez, interpreta la

8 Cf. M. Schambeck, Contemplatio als Missio. Zu einem Schlüsselphänomen bei Gregor dem Grossen (Studien zu systematischen und spirtuellen Theologie, 25; Würzburg 1999).

9 J. Rico Pavez, Introducción, Gregorio Magno, Libros Morales /1 (I-V), (Biblioteca de patrística, 42; Madrid-Buenos Aires, Santafé de Bogotá-Montevideo-Santiago 1998) 39; Cf. V. Recchin, Gregorio Magno: Papa ed esegeta biblico (Bari 1996) 355-404.

10 J. Fontaine, «Agustin, Grégoire et Isidore: Esquisse d'une recherche sur le Style des Moralia in Iob», en Colloques internationaux de CNRS, Grégoire le Grand (Paris 1986) 499-509.

11 Cf. J. Rico Pavez, op.cit., 41: «No es que haya que buscar en la Biblia un "recetario" para cada situación de la existencia humana; si es fuente constante de inspiración y regla constante para la vida es, justamente, por su carácter vivo».

12 Albertus Magnus, «Super Mysticam Theologiam Dionysii et Epistulas», en Alberti Magni Opera Omnia, XXXVIII, 2 (Münster 1978) (= SMT; SEP). Alberto Magno, Sobre la Teología Mistica de Dionisio - Super Mysticam Theologiam Dionysii. Según el texto de la Editio Coloniensis traducido y editado por Anneliese Meis, Latín-español (Anales de la Facultad de Teología, 491 / 2; Santiago 2008) (= STM). Para las Epistulas se usa traducción propia del borrador.

13 Respecto al ante nos hactenus indiscusso de Gregorio cf. J. Rico Pavez, op.cit., 18: «Hoy sabemos, en efecto, que el comentario de Gregorio no es el único, ni el más antiguo, que nos ha legado la tradición patrística».

14 J. Rico PAvez, op.cit., 17-21. Cf. M. Doucet, «"Vera philosophia”. L’existence selon saint Grégoire le Grand», Collectanea Cisterciensia 41 (1973) 227-252. Se usa la tra- 
intelección de dicho esfuerzo en cuanto prefiguración de Cristo, aplicándola a la vida de los cristianos ${ }^{15}$, sobre todo, en los momentos difíciles que les cabe vivir ${ }^{16}$.

Alberto Magno, por su parte, orienta su Comentario al Corpus Dionisiacum de la misma manera que Gregorio por la revelación de este Misterio, que busca entender racionalmente. Pese a que el Doctor Universalis se sirve de una gran cantidad de testimonios literarios, tanto de autores filosóficos como teológicos, vale la pena detenerse en las citas tomadas de los Moralia en SMT II, la Ep I, la Ep V y la Ep IX, para descubrir cuál es, concretamente, la influencia de Gregorio Magno sobre Alberto Magno en la intelección del problema razón y revelación. Elaboremos una respuesta aproximativa a esta pregunta, tomando en cuenta el contexto inmediato de la argumentación albertina de las citas, para analizar el campo conceptual hermenéutico y finalmente precisar el significado teológico de aquella propuesta que emerge del SMT y SEP en cuanto solución al problema razón y revelación.

\section{El «balbuceo» entre razón y revelación}

La primera referencia explícita a Gregorio Magno se encuentra en el capítulo II del SMT, dedicado a la «unitio ad deum», allí donde Alberto Magno trata de esclarecer la vía negativa a través de tres cuestiones, cuya primera es «si por el no ver y no conocer podemos conocer y ver a Dios» ${ }^{17}$. Entre las cuatro dificultades que presenta esta cuestión, la tercera reza: «aunque el no-ver esto a causa de algo Dios es visto, pone algo o nada... y así más debe ser significada la vía de conocimiento divino por afirmación que por negación de la visión $\rangle^{18}$. Ante tal preferencia aparente por la vía afirmativa en desmedro de la negativa, el Doctor Universalis evoca a Gregorio Magno, explicando:

ducción de J. Rico Pavez, op.cit., supra nota 8 y la de A. Alvarez De Toledo, Los Morales del Papa San Gregorio Magno (Buenos Aires 1945).

15 C. STRAW, Introduction, Grégoire le Grand, Morales sur Job / Sixiéme partie, livres XXVIII-XXIX (SC 476) (Paris 2003) 51-59.

16 R. A. MARkus, Gregory the Great and his World (Cambridge 1997).

17 SEP 466, 85: «utrum per non-videre et non cognoscere possimus deum cognoscere et videre».

18 STM, 88. 
«Porque no es pura negación, pero es negado el modo natural de la visión y queda la recepción de la luz sobrenatural, que a pesar de todo se da a conocer más por la negación, que no encontramos algo conocido para nosotros, que propiamente de Dios predicamos, a causa de la eminencia de la simplicidad, ya que la verdad de una predicación se funda en alguna composición, pero, así como dice Gregorio, casi “balbuciendo" hacemos resonar "la eminencia de Dios"»"

Alberto se refiere aquí a Moralia I 5 c.36 n.66, donde Gregorio interpreta Jb 4,16: «Se alzó. No reconocí su rostro, pero su imagen seguía ante mis ojos. Silencio [...] Después oí una voz». El Papa explica parte de este versículo así:

«Se dice que los fieles participan de su conocimiento "en algo" o "un poco", aun cuando El siempre permanece uno y el mismo, y no se le puede conocer por partes, ni se puede aceptar el hablar de una partición de su sustancia. Pero como no podemos expresarnos adecuadamente, obstaculizados por la limitación de nuestra humanidad como débiles niños, hablamos de Él balbuciendo algo de su misterio» ${ }^{20}$.

Esta explicación emerge desde el comentario que el Santo Papa elabora en los números 61-67 en cuanto explicación del sentido moral de Jb 4,16. En el contexto inmediato del n. 66 se constata elementos conceptuales que configuran un cuadro teológico fascinante, estableciendo un nexo profundo entre el ser humano, creatura racional, creada a imagen de su autor, el Hijo, Imagen del Padre ${ }^{21}$. Gregorio reconoce en el hombre aquel ser en el cual se recapitula toda la creación -Gn 1,26- dentro del orden jerárquico de la realidad desde dentro hacia fuera, lo cual garantiza el conocimiento «en algo» de Aquél que en su sustancia no se puede conocer, «la mente humana no puede captar la estabilidad de la divinidad, por eso

$19 S M T, 466,78-86$ : «quia non esta pura negatio, sed negatur modus naturalis visionis et relinquitur susceptio supernaturalis luminis, quod tamen magis notificatur per negationem, eo quod non invenimus aliquid notum nobis quod proprie de deo praedicemus, propter eminentiam simplicitatis, cum praedicationis veritas fundetur in aliqua compositione, sed, sicut dicit Gregorius, quasi "balbutiendo" "excelsa dei" resonamur».

20 Mor 5 (CCH. SL 143) 264, 26-265, 33: «si tamen dici illo uel parum uel aliquid potest, qui unus semper et idem permanens, intellegi partiliter non potest et tamen a suis fidelibus participari dicitur cum in eius substantia pars nullatenus admittatur. Sed quia hunc exprimere perfecto sermone non possumus, humanitatis nostrae modulo quasi infantiae imbecillitate praepediti, eum aliquantenus balbutiendo resonamus».

$21 \operatorname{Mor} 5$ (CCH. SL 143) 264, 26-265, 33. «Rationalis uero creatura eo ipso quo ad imaginem auctoris est condita ne nihim transeat figitur...», 63. «Imago quippe Patris. Filius est sicut de condito humana», 64 . 
Nuestro Redentor vino a nosotros en carne, creado, nacido, muerto, sepultado, resucitado, vuelto al cielo, mostrando la divinidad como pasando» ${ }^{22}$.

Cuando Gregorio, basándose en Ex 24,1 y 1R 19,11ss, pasa desde la visión-no-visión al sonido, la voz suave, que se escucha, el autor concluye que como el ver parcial se concreta en un hablar parcial, un balbuceo en la resonancia del misterio. El nexo concreto entre la razón y la imagen revelada es el Espíritu ${ }^{23}$, quien, «cuando se da a conocer a la debilidad humana, se manifiesta como sonido de viento impetuoso y como voz de brisa suave [...] suave, porque adecua su conocimiento a nuestros sentidos para que pueda ser conocido, impetuoso porque por más que se adecue, su venida luminosa perturba la ceguera de nuestra debilidad. Su luz nos toca con suavidad, pero golpea fuertemente nuestra indigencia» ${ }^{24}$. El Santo Papa esboza aquí el acceso al misterio de Dios, siempre eminente, que se abre y conserva a la vez su índole enigmática misteriosa de visión que también es audición ${ }^{25}$. Resulta decisivo el paso del ver al oír, de la receptividad a la actividad simultánea a través de la voz, que por muy sutil que sea, es decisiva para la recepción de la revelación de parte de la razón.

Si Alberto evoca esta interpretación gregoriana de Jb 4,16, fundamenta la unión con Dios, es decir, el modo por el que el intelecto debe unirse a Dios y con la voz alabarlo a él mismo ${ }^{26}$, en la «tiniebla supralúcida» que, al igual que el ver-no ver y el oír-no oír, designa una posibilidad permanente de la creatura racional de encontrarse sumergida en la revelación del misterio, sin poder expresarlo conceptualmente ni agotarlo verbalmente, sino que lo «balbucea». Queda abierta la pregunta: ¿por qué el Doctor Universalis reemplaza el «misterio» gregoriano por la «eminencia» dionisiana, cuando habla de su «resonancia» concreta por medio del creyente? Pese a que habría que investigar la cuestión más a fondo, trasunta aquí un dato importante: en el «misterio» gregoriano trasluce el Dios Trino del contexto, mientras que en la «eminencia» resalta la simplicidad del Dios

$22 \operatorname{Mor} 5$ (CCH. SL 143) 63.

23 P. CATRY, «Les voies de l'Esprit chez Grégoire», en Colloques internationaux du CNRS, Grégoire le Grand (Paris 1986) 207-225; ídem, Parole de Dieu, amour et Esprit-Saint chez. Saint Grégoire le Grand (Bigrallez-en-Mayes 1984); ídem, «Désir et amour de Dieu chez saint Grégoirele Grand», RechAug, 10 (1975) 269-303.

$24 \operatorname{Mor} 5$ (CCH. SL 143) 65.

25 M. SchAmBECK, op.cit., Menos frecuente es «oído del corazón», «auris cordis, auris intelligentiae».

26 STM, 83. 
La influencia de Gregorio Magno en Alberto Magno | 351

Uno, de mayor influencia dionisiana, lo cual no significa que el Doctor Universalis no preste atención a esta dimensión trinitaria, cuando afina el significado del «misterio» y sus derivaciones, sobre todo, el adjetivo «místico», en SMT y SEP.

\section{La sobreeminencia de Dios y su conocimiento en la mayor cercanía}

La segunda referencia de Alberto a Gregorio Magno se encuentra en la Ep I a Gayo, quien pregunta: «¿ Cómo es posible que el aumento de la lury de las cogniciones, en vez de traer mayor claridad y conocimiento, traigan mayor oscuridad e ignorancia?, $)^{27}$. El Doctor Universalis ofrece su solución a las objeciones que cuestionan referentes al ser de Dios y la posibilidad de conocerlo, afirmando:

«A esto, [respondemos], como dice el mismo Dionisio, que las tinieblas se causan de dos maneras: o desde el defecto de la luz, y así es verdad, que multiplicada la luz se atenúan y se destruyen las tinieblas; pero cuando las tinieblas se causan desde la abundancia de la luz y exceden sobre la virtud cognoscitiva, y entonces, en cuanto mayor es la luz, tanto más se multiplican las tinieblas; efectivamente, desde la luz de la luna no se ciegan los ojos como desde la luz del sol. Del mismo modo, en cuanto mayor cognición tenemos de Dios, tanto más conocemos la eminencia de Él mismo sobre nosotros, y así más encuentra faltar nuestro intelecto a la comprensión de Dios. De donde dice Gregorio, que entonces alguien se estima más ser lejos de Dios, cuando más cerca suyo se acerca» ${ }^{28}$.

La referencia a Gregorio la toma Alberto de Moralia I 24 c.6 n.11, donde el autor comenta a Jb 33,26: «Rogará a Dios y le otorgará su favor, contemplará con alegría el Rostro del que devuelve al hombre su integridad». Afirma el Santo Papa:

«Primero se limpia de la vista del alma con el fuego de la tristeza la obscuridad de los males, y entonces es alumbrada arrebatadamente con el resplandor y la claridad de la lumbre incomprensible. Y siendo

27 Así sintetiza Julio Söchting el complejo desarrollo de la primera Epistula.

28 SEP I 480, 26-38: «Ad hoc dicendum est, sicut dicit ipse Dionysius, quod tenebrae causantur dupliciter: aut exdefectu luminis, et sic verum est, quod multiplicato lumine attenuantur et destruuntur tenebrae; sed quandoque tenebrae causantur ex abundantia luminis et excessu super virtutem cognoscitivam, et tunc quanto maius est lumen, tanto magis multiplicantur tenebrae; ex lumine enim lunae non obtenebratur oculus sicut ex lumine solis. Similiter quanto maiorem cognitionem habemus de deo, tanto magis cognoscimus eminentiam ipsius super nos, et sic magis invenimus intellectum nostrum deficere a comprehensione dei. Unde dicit Gregorius, quod tunc aliquis magis se aestimat longe esse a deo, quando sibi magis prope est». 
de alguna manera vista esta luz, es al alma puesta en gozo de una seguridad; y como arrebatada sobre sí después del desfallecimiento de la vida presente, es de alguna manera tornada a crear la vida en cierta novedad. Allí el alma es rociada por la inmensa fuente del rocío soberano, allí contempla cómo no es suficiente para aquello que sobre sí es arrebatada, y, sintiendo la verdad, es cómo no puede ver cuánta es aquella verdad. De esta verdad se estima tanto más lejos cuanto más se acerca a ella, porque si de alguna manera no la viese no sentiría cómo no la puede ver ${ }^{29}$.

Esta afirmación evoca la fuente eterna en cuanto origen fundante de toda revelación sobreeminente de Dios en esta vida. Más que un esfuerzo teórico por conocer y ver racionalmente a Dios, entra en juego «el sentir la verdad», es decir, un énfasis práctico, el «sentido moral», que Gregorio ausculta dentro del contexto de Moralia 24,9-12, centrado en la encarnación. La cercanía sentida de la verdad, en la lejanía de la sobreeminencia de la luz divina, se entiende, fijándose en Jesucristo, quien aparece rezando en su agonía, -24,9- y experimenta aquel gozo -24,10- que al alma sólo se llega después de haber sido purificada -24,11-, pues «entonces es alumbrada arrebatadamente con el resplandor y claridad de la lumbre incomprensible»-24,11-. Resulta significativo que Gregorio, siguiendo a Jb 33,26, explicite el modo de ver a Dios a través de Jesús, en cuanto interrelación con «cara de Dios». Afirma, «porque conocemos por la cara a cada uno, llamamos no sin razón su cara al conocimiento de Dios» -24,12-. Y concluye: «El alma elevada a contemplación para considerar el conocimiento de la divina presencia que puede sentir y no cumplir, dícese rectamente después de tantos trabajos de este hombre tentado: "Verá su cara en alegría"»-24,12-.

Sin recurrir, como Gregorio, al sentir en cuanto clave cognoscitiva, Alberto se sirve de la idea subyacente al texto gregoriano, y presente en su contexto, es decir, la paradoja de a mayor lejanía mayor cercanía. El

29 Mor 24 (CCH. SL 143) 1195, 29-1196, 40: «Prius a mentis acie exurente tristitia interposita malorum caligo detergitur, et tunc resplendente raptim coruscatione incircumscripti luminis illustratur. Quo utrumque conspecto, in gaudio cuiusdam securitatis absorbetur; et quasi post defectum uitae praesentis ultra se rapta, aliquo modo in quadam nouitate recreatur. Ibi mens ex immenso fonte infusione superni roris aspargitur; ibi non se sufficere ad id quod rapta est contemplatur, et ueritatem sentiendo, uidet quia quanta est ipsa ueritas, no uidet. Cui ueritati tanto magis se longe existimat, quanto magis appropinquat, quia nisi illam utrumque conspiceret, nequam eam conspicere se non posse sentiret». 
Doctor Universalis argumenta, primero, con énfasis en la luz, basado en Jn 1,5 -cita bíblica que evoca en la primera objeción, pero que luego hace desembocar en la cita gregoriana-. Esto significa que la comprensión albertina confluye con la de Gregorio en el hecho del Verbo encarnado, donde el sentimiento y la razón se compenetran maravillosamente. Pero, pese a la coincidencia básica en la dimensión cristológica, que ambos autores resaltan, parece faltar a la explicación albertina el rostro, aunque su comentario a las Epistulas III-IV es de gran profundidad crística, mientras Gregorio se detiene en él, en cuanto lugar teológico por excelencia de un conocimiento perfilado de Dios, quien en la lejanía sobreeminente se hace cercano a través de su Hijo. Queda abierta la pregunta por el significado profundo que establece Alberto entre la figura de Cristo y el trascendental bonum en SEP VIII y por la relevancia de los trascendentales en general.

\section{La razón, compenetrada por el amory la revelación}

La idea de la «sobreeminencia en la cercanía mayor», comentada en la cita anterior, encuentra un eco significativo en el texto gregoriano, que la edición crítica cita como referencia implícita, texto que explicita, de modo peculiar, la relación razón y revelación. En efecto, Gregorio constata en dicho texto:

«Dios sólo es visto de lejos aun por los elegidos. Todo hombre por el mismo hecho racional de ser creado debe por la razón colegir que el que le hizo es Dios. Y ciertamente no es otra cosa verle ya sino mirar con la consideración su señorío divino. Pero cuando dice el texto: Todos los hombres le ven, añádese rectamente: $Y$ cada uno le mira de lejos: porque mirarle de lejos es no verle por presencia, sino considerarle por sola admiración de sus obras. También los escogidos le ven aquí desde lejos porque aún no comprenden su claridad por la sutileza de la vista interior; y, aunque por amor están ya cerca de Él, aún de Él están apartados por la carga de la morada terrenal; $y$, porque viviendo bien 
están allegados a Él, suspiran porque de la figura de su contemplación están lejos» ${ }^{30}$.

Se trata aquí de un extracto de Moralia I 27, c.5 n.8, texto dedicado a la explicación de Jb 36,25 (las obras): «Todos los humanos las contemplan, todos los hombres de lejos las perciben». En su explicación Gregorio se refiere no sólo explícitamente a la razón y el desafío de la sobreeminencia del conocimiento de Dios, estando el elegido todavía en la «morada terrenal», sino que insiste en que la cercanía mayor se produce a partir del amor. Cabe recordar que para Gregorio los sentidos descubren la relatividad del mundo y del tiempo, interrumpida por el pecado original y que partiendo de la tradición agustiniana el Santo Papa considera el corazón como lo más interior del hombre, como símbolo del «misterio del hombre», que tiene sus propios sentidos, los espirituales. Efectivamente, el corazón es la sede de lo espiritual-racional y lo sensorial, que descubre la relación del hombre con lo espiritual ${ }^{31}$. Su explicación encuentra el ojo del espíritu en el amor, pues «¿qué otra cosa es el amor que el ojo del espíritu?»32.

De ahí que el Santo Papa no distingue entre cuerpo y espíritu, sino entre bienes terrenos y temporales. Por lo cual resulta importante que Gregorio insista en que los elegidos ven a Dios desde lejos, «porque aún no

30 Mor 27 (CCH. SL 143) 1335, 1-14: «Omnes homines nident eum, unusquisque intuetur procul. Omnis homo eo ipso quo rationalis est conditus, debet ex ratione colligere eum qui se condidit Deum esse. Quem nimirum iam uidere est dominationem illius ratiocinando conspicere. Cum uero dictum sit: Omnes homines vident eum, recte subiungitur: Unusquisque intuetur procul. Procul quippe eum intueri est non iam illum per speciem cernere, sed adhuc ex sola operum suorum admiratione pensare. Procul illum hic etiam electi conspiciunt, quia necdum claritatem illius per acumen intimae uisionis apprehendunt. Cui etsi iam per amorem iuxta sunt, adhuc tamen ab illo terrenae inhabitationis pondere disiunguntur; et quamuis ei bene uiuendo inhaereant, a contemplationis eius specie longe se esse suspirant».

31 Por eso Gregorio habla de religiosa mens, ojo del espíritu (oculus mentis, cordis, oculi mentis) spiritualis oculi, oculi intelligentiae.

32 Cf. Mor 5, 86 (CCH. SL 143). Cabe recordar la fórmula Amor ipse notitia est que se sitúa en las homilías, donde Jesús se encuentra hablando a los discípulos y sin llamar mucho la atención, en la misma frase, Gregorio pasa de los discípulos a nosotros, de su exigencia a la nuestra: Jesús ha hecho conocer a los discípulos los gozos del cielo, las fiestas de la patria de lo alto, que se imprime cada día a nuestros espíritus por impresión de su amor. ¿Descuido de Gregorio? Se puede explicarlo así, cuando Gregorio pasa de los discípulos a las experiencias de sus auditores, al menos que no sea a lo inverso. La experiencia a la cual Gregorio se refiere es una experiencia de amor de las cosas de lo alto. Este texto muy breve distingue dos etapas de conocimiento y amor. 
La influencia de Gregorio Magno en Alberto Magno | 355

comprenden su claridad por la sutileza de la vista interior, y aunque por amor están ya cerca de Él». La distinción entre lejanía y cercanía, es decir, entre razón y amor, tiene una fuerte proyección escatológica hacia la vida eterna, donde ambas dimensiones se identifican en cuanto realizadas.

Si bien Alberto no explicita mayormente el amor en el texto señalado, sin embargo, no cabe duda de que todo su comentario atestigua una singular importancia del amor, como también de la dilectio, menos frecuente estadísticamente, y la caritas, escasamente nombrada ${ }^{33}$. De todos modos, el Doctor Universalis señala la necesidad que tiene la razón humana para integrar la dimensión afectiva en una racionalidad amorosa, que efectivamente aborda el misterio de Dios revelado. De ahí que comprende el quehacer teológico a partir de su singular definición: «la teología es una ciencia afectiva» ${ }^{34}$. Igual como en Gregorio, para Alberto esto no es un problema teórico sino de praxis, que involucra a todo el ser humano, ya que la unión por medio del amor suple la incapacidad connatural de la razón humana para unirse a dicho misterio, a la vez, lejano y cercano. Los detalles fascinantes que Alberto aporta al respecto quedan por investigar.

\section{El permanente ejercicio del no-ver, viendo a través de la «nube»}

Al iniciar su comentario a la Ep $V$, dedicada a la espesa nube, que envuelve al origen fundante de todo cuanto existe, la causa essendi, Alberto cita doblemente a Gregorio. Comentando a Dionisio, el Doctor Universalis afirma:

«La oscuridad espesa es lur inasequible etc. No me ve ningún hombre y vive, Ex 33,20. Respecto a esto, dice Gregorio que nadie mientras está viviendo vida humana puede ver a Dios. Quien se concentra hacia la luz del interior debe cerrar los ojos a la luz exterior, como él mismo dice. Pero esta luz del exterior es la luz de la vida humana connatural al hombre, y por eso, Dios no puede ser visto, a no ser que abandonada la vida, que es por la luz humana, comienza a vivir hasta cierto punto la divi-

33 Algunas afirmaciones importantes: «sed est vere homo, qui amator hominum, idest ex amore, quem habuit ad homines, differenter est super homines et secundum homines»; «sed per voluntatem, et ideo sunt alliciendi ad amorem veritatis, quamvis e converso modo sit procedendum, quando veritas cogit, per demonstrationem»; «Sed significatur deus sicut causa amoris, qui significatur in igne, et ipsum donum in se consideratum ante participationem significatur ut essentia quaedam».

34 Alberto define la Teología como una «scientia affectiva» en In Sententiarum d.1 a. 4.S.19ª Cf. I. Craemer-Ruegenberg, Albertus Magnus. Völlig überarbeitete, aktualisierte und mit Anmerkungen versehene Nenauflage der Originalausgabe, Herausgegeben von Henryk. Anzulewicz. (Leipzig 2005), op. cit., 55; 60s; 169. 
na por la participación de la luz divina. Y por eso Dios no puede ser visto, a no ser, en las tinieblas de la luz humana connatural a nosotros, y por eso puede extraer de las palabras propuestas por la materia de esta epístola, en la que Dionisio responde a Doroteo, el ministro, esto es, el diácono, quien pregunta por la nube espesa en la cual se dice que Dios es visto» ${ }^{35}$.

El texto, que Alberto tiene en mente aquí, y que reproduce de modo sintetizado, en cuanto a sus ideas básicas, es Moralia I 18 c.54 n.88-92. Se trata de una explicación que Gregorio ofrece respecto a Job 28, 20-21: «¿De dónde viene la sabiduría? ¿Dónde se encuentra la Inteligencia? Se hurta a los ojos de todo viviente, se esconde a los pájaros del cielo». La extensa explicación de este versículo abarca los números 88-92, que no son tomados en cuenta por Alberto en su totalidad, ni son citados, sino acogidos en su ductus básico. Éste resalta a través de sus momentos claves, que avalan lo señalado por el Doctor Universalis. Las afirmaciones de mayor relevancia para la comprensión de la interiorización de una visión no viendo y viceversa, es decir, a través de la nube, rezan así:

«Es de considerar con mucha diligencia la pregunta de este santo varón acerca de dónde venga la sabiduría, como sea cierto que viene de Aquél del cual es nacida. Mas porque nace del Padre invisible y coeterno, es su camino oculto [...] Pero el lugar de su inteligencia es el alma humana, a la cual hace aquí santa la Sabiduría de Dios cuando la llena [...] Pero esto que luego se dice es muy de maravillar: Está escondida a los ojos de todos los vivientes. Porque si la Sabiduría que es Dios fuese escondida a los ojos de todos los vivientes, cierto es que ninguno de los santos la hubiera visto [...] Pero cuando miro a los Padres del Antiguo Testamento, conozco por testimonio de su lectura que muchos de ellos han visto a Dios[...] Jacob[...] Moisés[...]Job[...] Miqueas[...] ¿qué se da a entender manifiestamente sino que, mientras aquí vivimos mortalmente, puede ser Dios visto por la misma especie de su naturaleza?, pero el alma, inspirada por la gracia del Espíritu Santo, ve a Dios

35 SEP V 493, 4: «Super quo dicit GREGORIUs, quod nullus humana vita vivens deum videre potest. Qui enim ad interius lumen se colligit, oportet, quod ab exteriori lumine oculus claudat, sicut IDEM dicit. Hoc autem lumen exterius est humanae vitae lumen connaturale homini, et ideo deus videri non potest, nisi deserta vita, quae est per Humanum lumen, divina quidam vita vivere incipiat participatione divini luminis. Et ide deus non potest videri nisi in tenebris luminis humani connaturalis nobis, et ideo ex verbis propositis potest trahi materia istius epistulae, in qua respondet Dionysius Dorotheo ministro, id est diacono, quaerinti de caligine, in qua dicitur deus esse et videri». 
por algunas figuras pero no podrá tocar la fuerza de su divina esencia $[\ldots]$ no pudo ser vista por la lumbre incomprensible de la eternidad $\iota^{36}$.

Resalta un nexo destacado en el origen de la sabiduría, el Padre invisible y coeterno y el alma humana llenada por dicha sabiduría y así santificada. La índole escondida de esta relación es punto de partida de la exégesis gregoriana, que junto con el no ver destaca la posibilidad de haber sido vista precisamente por hombres privilegiados. Esta imposibilidad de ver a Dios mientras vivimos en este mundo, a la vez que se dé la posibilidad de haber Él sido visto por algunos hombres privilegiados, explicita el Santo Papa ${ }^{37}$ :

«Nadie ve a Dios si no muere carnalmente en este mundo. Mas si la eterna claridad de Dios puede ser vista en una altura de contemplación por algunos vivientes en esta carne mortal, los cuáles han crecido en virtud inestimable, aun esto no contradice la sentencia del bienaventurado Job que dice: Está escondida a los ojos de todos los vivientes, porque cualquiera que vio la Sabiduría, que es Dios, del todo muere en cuanto a esta vida, para que ya no sea tenido por su amor [...] Y de aquí es que aún se dice al mismo Moisés: No me verá hombre alguno y vivirá; como si dijese claramente: ninguno jamás vio a Dios espiritualmente, el cual viviese carnalmente en este mundo. Y por eso san Pablo, el cual, como él también testifica, había en parte conocido las cosas invisibles de Dios, ya se decía ser del todo muerto en cuanto a este mundo: El mundo es crucificado para mí, y yo para el mundo [...] Si por ventura están dos en un lugar, de los cuales uno está vivo y otro muerto, cierto es que, aunque el muerto no vea al vivo, el vivo ve al muerto[...] $»^{38}$. «(Jesús) mismo lo

36 Mor 18, 88 (CCH. SL 143) 950, 3ss: «Pensandum magnopere est quod a sancto uiro requiritur unde sapientia ueniat. Ab eo etiam uenit a quo orta est. Sed quia ab inusibili et coaeterno Patre nascitur, eius uia occulta est [...] Locus uero intelligentiae euis, est humana mens, quam haec Dei sapientia dum repleuerit, sanctam facit [...] Sed hoc ualde mirum est quod protinus subinfertur: Ascondita est ab oculis omnium ninentium [...] Sapientia quippe quae Deus est, si omnium uiuventium oculis occulta esset, hanc procul dubio sanctorum nemo uidisset [...] Rursumque cum testamenti ueteris patres intueor, multos horum, teste ipsa sacrae lectionis historia, Deum uidisse cognosco [...] Iacob[...] Moyses[...] Iob [...] Michaeus [...] nisi hoc quod patenter datur intelligi, quia quamdiu hic mortaliter uiuitur, uideri per uasdam imagines Deus potest, sed ipsam naturae suae speciem non potest».

37 Cf. P. AUBIN, «Intériorité et extériorité dans les moralia in Job de Saint Grégoire le Grand», Recherches Science religieuse 62 (1974) 117-166.

38 Mor 18, 88 (CCH. SL 143) 952, 54ss: «Deum nemo nidit umquam [...] Sin vero a quibusdam potest in hac adhuc corruptibili carne uiuentibus, sed tamen inaestimabili uirtute crescentibus, quodam contemplationis acumine aeterna Dei claritas uideri; hoc quoque a beati Iob sententia non abhorret qui ait: Abscondita est ab oculis omnium ninen- 
promete: El que me ama será amado por mi Padre, y yo le amaré y me manifestaré a mí mismo a él; como si dijese claramente: Los que me miráis en vuestra naturaleza resta que me veáis en la mía [...] y de aquí es que dice san Pablo: Ahora le vemos por espejo en semejanza, pero entonces le veremos cara a cara. Abora conozco en parte, mas entonces conoceré como soy conocido» ${ }^{39}$.

Aquí el análisis del Santo Papa especifica más lo exterior, lo carnal, que impide ver «la sabiduría que es Dios» y la dimensión interior, en la cual emerge después de haber muerto la manifestación de Hijo amado del Padre. Entonces resulta clave la muerte a lo carnal para ver a Dios, a la vez que el inicio de dicha visión ya centrada en Jesús, Dios encarnado. El texto paulino 1Co 13,12 subraya el todavía no del ya iniciado ${ }^{40}$. Lo cual Gregorio explicita, cuando en el párrafo siguiente se refiere a los ángeles, que siempre ven y siempre desean ver, de tal modo que resalta otra dimensión propia de la existencia creatural, la dinámica temporal, en su tensión de cambio. Afirma Gregorio respecto de la creaturas angelicales, que: «Son hartados sin hastío, porque la misma hartura se enciende siempre con el deseo» ${ }^{41}$. La paradojal imposibilidad de ver a Dios no viéndolo, emerge desarrollada por Gregorio de modo gradual, dejando en claro la estrecha interrelación del ver por medio de la razón con la praxis de una vida liberada de las actitudes mundanas. Gregorio contrapone la exterioridad a la interioridad del alma, la carne al espíritu, el ya y el todavía no. La solución

tium: quoniam quisquis sapientiam quae Deus est, uidet,huic uitae funditus moritur, ne iam eius amore teneatur [...] Unde adhuc ad eumdem quoque Moysen dicitur: Non enim nidebit me homo et ninet. Ac si aperte diceretur: Nullus umquam Deum spiritaliter uidet, et mundo carnaliter uiuit.Vnde Paulus quoque apostolus, qui adhuc Dei inuisibilia, sicut ipse testator, ex parte cognouerat, iam huic mundo totum se mortuum esse perhibebat, dicens: Mibi mundus crucifixus est et ego mundo [....] Si enim duo fortasse in uno loco sint, quorum unus uiuus, alter uero sit mortuus, etsi mortuus uiuentem non uidet, uiuus tamen mortuum uidet[...]».

39 Mor 18, 90 (CCH. SL 143) 953, 99: «in se pollicetur dicens: Qui diligit me, diligetur a Patre meo; et ego diligam eum et manifestabo me ipsum illi. Ac si patenter dicat: Qui in uestra me cernitis, restat ut in mea me natura uideatis [...] Hinc Paulus dicit: Nunc uidemus per speculum in aenigmate, tunc autem facie ad faciem.Nunc cognosco ex parte, tunc cognoscam sicut et cognitus sum».

40 Se trata de un texto muy usado por autores afines a Gregorio, como p. ej. Guillermo de Saint Thierry. Cf. A. MeIs, El enigma del hombre, según Guillermo de Saint-Thierry, a la luz del encuentro entre cultura griega y latina (Anales de la Facultad de Teología, 54; Santiago 2004).

${ }^{41}$ Mor 18, 91 (CCH. SL 143) 953, 109. 
no esquiva la mediación cristológica, pero la concibe sólo pneumatológicamente posible «por su espíritu».

Cuando Alberto evoca esta dramática descripción al inicio de su comentario a la Ep $V$ de Dionisio, dedicada a la nube, sintetiza magistralmente el paso necesario del mundo exterior-carnal al interior- espiritual, con que plasma su respuesta a la pregunta de Doroteo, que «surgió de cierta repugnancia que se ve en la Sagrada Escritura, que en alguna parte le prohíbe habitar en la nube espesa, como está dicho en Ex 20, 21, que «ingresó Moisés en la espesa nube en la cual estaba Dios», 1R, 8, 12: «Dijo el Señor, que habitará en las nubes», y en el Salmo 18,12: «Porque puso tinieblas como refugio suyo». Y esto parece contradecir lo que el Apóstol dice en 1 Tm 6,16: «Que habita en la luz inasequible; que habita, pues, en la luz, no habita en una nube o en las tinieblas». El conjunto de los textos señalados por Alberto se avala por una frase significativa de Gregorio, quien afirma en Mor IV 36,62: «Actuando así, hace de sí misma como una escala por la que sube desde las cosas exteriores a la propia vida interior, y desde su interior tiende a su Autor. Cuando abandona las imágenes corporales y el alma entra en sí, no es poca cosa lo que ha hecho» ${ }^{42}$. Alberto, sin duda, ofrece una concreción ejemplar de este trasfondo gregoriano en la Ep $V$, centrada en la espesa nube, como un permanente ver no viendo, iniciado ya en cuanto speculum aeternitatis -SMT- de aquella plenitud de la patria.

\section{El traspaso del simbolo hacia la profundidad de los misterios}

Alberto se refiere finalmente a Gregorio en la Ep IX, dedicada a la justificación de la teología simbólica, como lo ha mostrado el profesor visitante Henryk Anzulewicz. Allí emerge, junto con la «belleza escondida», la «verdad divina» y la «bondad de la contemplación», la profundidad de los misterios, que los razonamientos humanos no alcanzan, lo cual no invalida la teología simbólica en cuestión, aunque Gregorio parece oponerse a ella como el Doctor Universalis constata, afirmando:

«[...]Gregorio dice que la Sagrada Escritura es un río en el cual el cordero pasa a pie y el elefante nada; y llama cordero a un fiel manso y humilde, que en sentido literal se alimenta de la Sagrada Escritura; de su parte el elefante es aquél que por la enorme capacidad del intelecto es elevado hacia los misterios, de los cuales no se puede alcanzar la

42 Mor Ep miss (CCH. SL 143) 62. 
$360 \mid$ Anneliese Meis

profundidad; pero aquello en que concierne al alimento espiritual no debe ser desechado; por lo tanto, los símbolos que se relacionan con el sentido literal no se deben destruir» ${ }^{43}$.

A diferencia de las citas anteriores Alberto se sirve esta vez del texto gregoriano en la parte de las objeciones, indicándolo en cuanto segunda objeción. El texto del Santo Papa en su carta a Leandro, con que introduce los Moralia, efectivamente reza así en el punto 4:

«Y es que, la Palabra divina, al igual que interroga a los doctos con sus misterios, también muchas veces reconforta a los sencillos con sus claros relatos. Con su claridad alimenta a los pequeños, con su profundidad deja perplejas las mentes de los más elevados. Es, en verdad, como un río, como ya he dicho, ancho y profundo, en el que tanto el cordero puede caminar, como el elefante nadan ${ }^{44}$.

Esta cita gregoriana rescata el sentido literal de los símbolos, que no deben «destruirse», a la vez que evoca la capacidad diversa de los oyentes, los sencillos capacitados para la claridad del sentido literal y las mentes más complejas para la profundidad de los misterios, es decir, el sentido alegórico. Ambos sentidos, sin embargo, se interrelacionan. El Santo Papa lo había explicado en el número 2 de la misma carta, cuando señaló:

«El que comenta la palabra sagrada debe comportarse como un río. Cuando un río, en efecto, a lo largo de su curso se encuentra con valles profundos se precipita en ellos con ímpetu y sólo cuando los llena suficientemente reemprende entonces su carrera. Así debe actuar también el comentador de la Palabra de Dios: cuando hable sobre un tema cualquiera, si encuentra ocasión para una adecuada edificación, debe desviar las aguas de su palabra al valle más cercano y volver al

43 SEP IX 534, 32-40: «Praeterea Gregorius dicit, quod sacra scriptura est fluvius, in quo agnus peditat et elephas natat; et agnum dicit mansuetum et humilem fidelem, qui reficitur in sensu litterali sacrae scripturae; elephas autem est, qui magnitudine intellectus elevatur ad mysteria, quorum non potest profundum pertingere; sed illud in quo contingit esse refectionem, non est abiciendum; ergo symbola, quae ad sensum litteralem pertinent, non sunt destruenda».

44 Mor Ep miss 4 (CCH. SL 143), 173: «Diuinus etenim sermo sicut mysteriis prudentes exerciet, sicut plerumque superficie simplices refouet. Habet in publico unde paruulos nutriat, seruat in secreto unde mentes sublimium in admiratione suspendat. Quasi quidam quippe est fluuius, ut ita dixerim, planus et altus, in quo et agnus ambulet et elephas natet». 
cauce del tema propuesto sólo cuando haya regado suficientemente el campo de esta enseñanza añadida ${ }^{45}$.

El ejemplo del río y su manera de proceder sirve al comentador para orientar el uso de los sentidos de la Sagrada Escritura, histórico, alegórico y moral, adaptándose al oyente, de tal modo que toda explicación sea para «una adecuada edificación». Efectivamente, vale que «el sentido histórico y el sentido alegórico (relativo al misterio cristiano) son considerados como las condiciones de acceso para captar el sentido moral [...] Pero conviene entender bien de qué sentido moral se trata. No es un simple "sentido práctico" o un "moralismo" plano de pura aplicación de una ley. Es, más bien, un sentido que está enraizado en el misterio revelado de Cristo en la "alegoría", lejos, por tanto, de cualquier extrinsecismo» ${ }^{46}$. Pues Gregorio llega a la conclusión que la Sagrada Escritura «crece» en la medida en que es leída ${ }^{47}$.

Al evocar Alberto esta referencia gregoriana en cuanto objeción a la destrucción necesaria de una auténtica teología simbólica, tal como la defiende el Doctor Universalis en la Epistula novena, admite la vigencia de tal teología, pero la aclara por medio de la contraobjeción explicativa de la solución, diciendo: «Se debe decir [...] que el sentido literal tiene dos significados en la Sagrada Escritura: en efecto, algunas veces es aquél que nos dan las palabras a primera vista, como cuando se dice que David venció a Goliat; por el contrario, otras veces no es el sentido literal el que nos da las palabras, sino el que capta las cualidades de aquellas cosas que se dan a conocer por medio de las palabras, escritas en otra parte también, porque esto es lo que el escritor quiere expresar y según de esta manera decimos que el sentido metafórico es literal a la manera que dice Is 37,29: "Pondré

45 Mor Ep miss 2 (CCH. SL 143) 4, 97: «Sacri enim tractator eloqui morem fluminis debet imitari. Fluuius quippe dum per alueum defluit, si ualles ex latere concauas contingit, in eas protinus sui impetus cursum diuertit, cumque illas sufficienter impleuerit, repente sese in alueum refundit. Sic nimirum, sic diuini uerbi esse tratactor debet, ut, cum de qualibet re disserit, si fortasse iuxta positam occasionem congruae aedificationis inuenerit, quasi ad uicinam uallem linguae undas intorqueat et, cum subiunctae instructionis campum sufficienter infuderit, ad sermonis propositi alueum recurrat».

46 Cf. D. Ramos-Lisson, «En torno a la exégesis de San Gregorio Magno sobre el “Cantar de los Cantares"», Teología y Vida, XLII (2001) 245-248.

47 Mor 20, 1,1 (CCH. SL 143) 1003, 10-12: «quod aliquo modo cum legentibus crescit, quod a rudibus lectoribus quasi recognoscitur, et tamen doctis semper noua reperitur». Cf. A. Simon, op.cit., 12. 
un anillo en tu nariz y te haré caer en tierra, de donde viniste"; en efecto, el profeta quiere referirse a Senaquerib, no a algún búfalo salvaje, que debe ser regresado a la tierra de los asirios. $Y$ de esta manera decimos que tales significados de los símbolos no se refieren al sentido literal, sino más bien a lo que es dado de entender por parte de ellos por alguna semejanza; y por tanto, se deben descartar y solamente se debe retener la verdad representada por ellos».

El Doctor Universalis aclara así el uso del sentido literal, legitimando la cita gregoriana, a la vez que vuelve, por decirlo así, al comienzo del círculo hermenéutico del problema razón y revelación, expuesto en nuestro breve estudio, es decir, el balbuceo inicial del misterio de Dios, la sobreeminencia de lejanía en mayor cercanía, el ejercicio permanente del no ver viendo para los diversos destinatarios de la revelación de Dios, limitados o sobredotados en su capacidad racional. No cabe duda, sin embargo, de que tanto para Gregorio como para Alberto Magno la capacidad intelectual receptiva respecto del don de Dios, su sabiduría, se verifica por una actividad amorosa concreta, orientada por el rostro de Dios y del hermano.

\section{A modo de conclusión}

Cabe señalar que las referencias a Gregorio Magno en el Corpus Dionisiacum de Alberto Magno explicitan ejes transversales del pensamiento de ambos autores, que confluyen en una fecunda intelección, que garantiza la comprensión auténtica de Alberto Magno respecto de su fuente, pero cuyo aporte trasunta en una novedad, especulativamente superior a la de su antecesor. La influencia parece ser más que la de una autoridad, un factor catalizador para una interpretación distinta, superior en su fuerza especulativa a Gregorio, inferior en la concreción cristalina de cercanía al texto bíblico y su proyección práctica. Los ejes más relevantes para el problema razón y revelación son:

1. El misterio del ser, pensado por Dionisio en cuanto antecedente del actus essendi de Tomás de Aquino y explicado como causa essendi por Alberto -Ep $V$-, es comprendido por Gregorio Magno de tal modo que la revelación del misterio de Dios se hace asequible a la razón humana en su profundidad trinitaria. El Santo Papa aporta al Comentario albertino, siempre fiel al pensamiento dionisiano en su fuerza especulativa y más bien tendiente a la unidad, aquella profundidad teológica que 
a la vez se torna práctica, es decir, resalta la trinidad económica que es la inmanente y viceversa, como afirma Rahner, aunque el Santo Papa no se refiere con frecuencia a dicho misterio.

2. No cabe duda de que tanto para Dionisio como para Alberto el ser llega a sí mismo a través de los entes, pero, Gregorio más que especulación, aporta la concreción y el rostro a la comprensión de dichos entes. De este modo, el Santo Papa permite a Alberto dar al pensamiento dionisiano, tendiente preferentemente a lo abstracto, aquellos contornos perfilados concretos que el Doctor Universalis busca verificar tanto en su especulación como en su conducta personal. Esto trasforma el problema razón y revelación en aquella apasionada aventura de libertad, que a nadie deja indiferente. Qué importancia cabe al respecto a los trascendentales, queda por investigar.

3. Si, finalmente, el ser y los entes se median tanto en Dionisio como en Alberto por una forma de participación, que involucra el amor -si pensamos en la importancia del amor, hasta erótico en el capítulo central de Div Nom y la afectividad, destacada por Alberto-, resalta, con fuerza, el sentimiento en cuanto clave antropológica del pensamiento gregoriano y albertino que une razón y revelación en aquella verdad, que sólo es comprensible por medio del Espíritu, a modo de la encarnación, es decir, en cuanto Amor ipse notitia est-Homilia in enang ii 7 (27)-. 
Resumen: Si bien la influencia de Gregorio Magno fue decisiva para la historia del pensamiento teológico práctico en la Edad Media, siendo Gregorio el autor más citado en la STh de Tomás de Aquino después de Agustín, su influencia sobre Alberto Magno no ha sido estudiada recientemente. En efecto, Alberto Magno orienta su Comentario al Corpus Dionisiacum de la misma manera que Gregorio por la revelación de este misterio, que busca entender racionalmente. El estudio se detiene en las citas tomadas por el Doctor Universalis de los Moralia en SMT II, la Ep I, la Ep V y la Ep IX, para descubrir cuál es, concretamente, la influencia de Gregorio Magno sobre Alberto Magno en la intelección del problema razón y revelación.

Palabras clave: Misterio, razón, revelación, amor, recepción.

Abstract: Although the influence of Gregory Magnus was crucial for the history of practical theological thought in the Middle Ages -being the most cited author in Thomas Aquinas' STh after Augustine- his influence over Albertus Magnus has not been studied recently. In effect, Albertus Magnus's Commentary on Corpus Dionysiacum is guided, in the same way as Gregory, by the revelation of this mystery, which he seeks to understand rationally. This study focuses on the citations from the Moralia that Doctor Universalis uses in SMT II (Super Mysticam Theologiam Dionysii), the Ep. I, the Ep. $V$ and the Ep. IX, in an effort to concretely discover what Gregory Magnus' influence was over Albertus Magnus in his understanding of the problem of reason and revelation.

Keywords: Mystery, reason, revelation, love, reception. 